REIMPRESIÓN

Rev Chil Salud Pública 2014 Vol 18 (3): 311-313

\section{UNA VIDA DEDICADA A LA SALUD PÚBLICA. ENTREVISTA A LA DRA. ANA MARÍA KAEMPFFER R.*}

El carro número 36 del tranvía Matadero-Palma era el que traía a una jovencísima Ana Kaempffer a su primer año en la vieja Escuela de Medicina, en 1943. Recién cumplía 17 años y era una de las 14 mujeres en un curso de 140 alumnos. De ellas, cuatro llegaron juntas al momento de egresar; de las otras, cinco se recibieron algo más tarde, debido a enfermedades que las obligaron a congelar el año, abandonaron la carrera o se cambiaron a otra.

Quien es hoy docente de la Escuela de Salud Pública de la Facultad de Medicina, en el área de Promoción de la Salud, cuenta que "éramos unos alumnos bastante pasables, teniendo en cuenta que veníamos saliendo de la enseñanza media, de un ambiente muy distinto. Por ello el primer año fue novedoso y estresante para muchos, vivíamos un poco asustados. Los exámenes eran orales, ante una comisión de tres profesores. La nota familiar la ponían Laurita y Rosita, que empezaron con un kiosco vendiendo sándwiches de queso y leche con vainilla”.

De aquellos profesores, explica que "tuvimos la suerte de contar con docentes de excepción, como el inolvidable Eduardo Cruz-Coke, quien era una especie de mago Merlín pues nos tenía fascinados por la calidad de sus clases y la elegancia de su oratoria. Tuvo la cualidad de mostrarnos que la medicina no solo consistía en diagnosticar y tratar pacientes, y que la enfermedad era pesquisable en etapas tempranas".

Asimismo, y respecto de la figura inconfundible del profesor Emilio Croizet, explica que "era vivaz y enérgico. Siempre lo vimos en mangas de camisa; cuando los jóvenes andábamos con abrigo, chaleco y bufandas de lana, él recorría los pasillos tan fresco. Fue uno de los más afectados por el incendio que destruyó la escuela (2 de diciembre de 1948), pues perdió su laboratorio, sus muestras y su biblioteca”.

AmANDa Fuller Facultad de Medicina, Universidad de Chile.

* La Dra. Ana María Kaempffer R. -docente e investigadora destacada de la Escuela de Salud Pública de la Universidad de Chile- falleció el miércoles 13 de agosto de este año. En recuerdo a su presencia entre nosotros y a su recordada labor en salud materno-infantil la Revista Chilena de Salud Pública reimprime una entrevista a ella por la Dra. Amanda Fuller y publicada en Huella y Presencia, tomo V, 2003, pp. 57-59. 
La malla curricular de entonces estipulaba que los estudiantes, en el cuarto año de la carrera, se distribuyeran en distintos centros hospitalarios. "Así fue como nos pusimos en contacto con grupos de ayudantes excepcionales, como el doctor Rodolfo Armas Cruz, grande en lo intelectual, en lo físico y espiritual, pues era un internista integral, magnífico docente, bondadoso y paternal. Por otra parte en Pediatría, quienes estábamos en la sede Oriente, del Hospital del Salvador, quedamos con los doctores Aníbal Ariztía y Julio Schwarzenberg; pese a que en el hospital veíamos niños desnutridos con enfermedades infecciosas, y nuestras armas terapéuticas eran bastante modestas, estos dos maestros encendieron la chispa vocacional que me llevó decididamente al campo de la salud infantil", explica agradecida.

Orientando aún más lo que sería su especialidad, la doctora Kaempffer agrega que en medio de las asignaturas clínicas tenían un curso denominado entonces Medicina Preventiva. "De la mano de los profesores Hernán Romero y Benjamín Viel conocí la importancia de la prevención y promoción de la salud de los niños, las abrumadoras tasas de mortalidad infantil y los factores que la condicionaban. Con ellos se cristalizó mi visión de futuro: la necesidad de participación de todos los sectores y el trabajo organizado a nivel colectivo".

\section{POR LA SALUD DE LOS NIÑOS}

Los recuerdos de la doctora Kaempffer nos revelan su persistencia en hacer realidad en su trabajo sus sueños de estudiante: es así como en sus tres primeros años de desempeño profesional, compartió su tiempo entre la cátedra de Pediatría del Hospital Calvo Mackenna y la Escuela de Salubridad, creada en 1944 y dirigida por el doctor Romero. En esos años, consiguió que el doctor Ariztía le permitiera usar parte de su horario en consultorios, con un programa de Control de Niño Sano, de manera que los alumnos conocieran en terreno las condiciones de vida de los menores: "Más tarde nos permitieron a dos de los 'nue- vos' ir a diario a revisar los recién nacidos en la Maternidad del Salvador antes de darles el alta, cosa que hasta el momento no se hacía".

Así fue como en 1954 el doctor Romero, "viendo el interés por la salud pública de dos de quienes fuimos sus ayudantes, nos propuso postular al curso principal, equivalente al magíster de hoy. Allí nos dijeron que estábamos "verdes" y que otro año de trabajo nos daría más experiencia; entonces él nos aconsejó postular a una beca Rockefeller, que obtuvimos, y a la Escuela de Salud Pública de la Universidad de Harvard, donde nos aceptaron pese a que la experiencia con matrimonios de estudiantes no había sido muy exitosa". El otro ayudante del que habla era el doctor Ernesto Medina, con quien se había casado recientemente. El doctor Hugh Leavell, que era el director de la escuela estadounidense, guió sus pasos: "Los míos a la salud materno-infantil y los de Ernesto al área del adulto y las enfermedades crónicas. Nos graduamos con un glorioso "cum laude" escrito debajo del grado de magíster”. A su regreso se reincorporó a lo que pronto sería la Escuela de Salud Pública.

\section{UN BALANCE}

- ¿Cómo ve la actual Escuela de Salud Pública? -A raíz de las diferentes situaciones económicas, toda la Universidad ha tenido que entrar en una política de autofinanciamiento. A diferencia del compromiso con la salud del país y con la universidad que tenemos quienes nos educamos casi gratis, hoy se corre el peligro de convertir a los egresados en profesionales más individualistas, porque han tenido que pagar o contraer una gran deuda.

Ahondando, la doctora Kaempffer explica que "la Escuela de Salud Pública, en todas sus épocas, a veces difíciles, ha mantenido en sus propósitos centrales el formar profesionales para servir a la población en forma organizada. Nuestra institución ha preparado especialistas no solo para Chile sino que para muchos países del continente, como Cuba, México, Venezuela, Honduras, El Salvador, Guatemala, Perú, Bolivia, Argentina, 
Uruguay y Colombia, y por ello en 1988 fue galardonada por la Organización Mundial de la Salud debido a su importante contribución para hacer realidad la meta de salud para todos".

Por otra parte, la especialista agrega que "ha sido posible incrementar el intercambio con universidades e instituciones de todo el mundo, como North Carolina, San Diego, Colombia, País Vasco y Granada. De hecho el actual director, el doctor Giorgio Solimano, es el director de la Asociación Latinoamericana de Escuelas de Salud Pública, ALAESP. Todo esto nos ha llevado a que este año se haya cumplido el deseo, largamente acariciado, de agregar a nuestro cursos de magíster, diplomado y otros, el doctorado en Salud Pública”.

Finalizando con una sonrisa, la doctora Kaempffer dice que "los docentes antiguos, por no decir "viejos", vemos con orgullo cómo los egresados alcanzan posiciones relevantes en el Ministerio de Salud o en las regiones en que se desempeñan; y cómo nos hemos ido acercando a las disciplinas clínicas y a los establecimientos de atención cerrada, lo que nos hace crecer a todos. 